\title{
Pengaruh Pasang Surut Terhadap Sebaran Material Padatan Tersuspensi di Pantai Dasun Kabupaten Rembang
}

\author{
Gentur Handoyo $^{1 * *}$, Petrus Subardjo ${ }^{1}$, Vemilarisa Kusumadewi ${ }^{2}$, Baskoro Rochaddi ${ }^{1}$, Sugeng \\ Widada $^{1}$
}

\author{
${ }^{I}$ Departemen Oseanografi, Fakultas Perikanan dan Ilmu Kelautan, Universitas Diponegoro \\ ${ }^{2}$ Program Sarjana Departemen Oseanografi, Fakultas Perikanan dan Ilmu Kelautan \\ Jl. Prof. H. Soedharto, SH, Tembalang Semarang. 50275 Telp/Fax (024) 7474698 \\ Email: *gentur.handoyo@live.undip.ac.id
}

\begin{abstract}
Abstrak
Indonesia memiliki laut yang sangat luas dibandingkan dengan daratannya. Luas total wilayah Indonesia adalah 7,81 juta $\mathrm{km}^{2}$ yang terdiri dari 2,01 juta $\mathrm{km}^{2}$ daratan, 3,25 juta $\mathrm{km}^{2}$ lautan, dan 2,55 juta $\mathrm{km}^{2}$ Zona Ekonomi Eksklusif (ZEE). Merupakan suatu Negara dengan luas perairan lebih besar dari pada luas daratan, maka dari itu Indonesia disebut sebagai Negara Maritim. Salah satunya dipulau jawa, tepatnya di daerah jawa tengah. Pantai Dasun terletak di wilayah Kabupaten Rembang, dimana lokasi tersebut sering dijumpai aktivitas kapal nelayan, destinasi wisata, kegiatan industri dan aliran sungai. Proses sedimen tersuspensi dipengaruhi oleh proses-proses yang terjadi di lautan seperti pasang surut dan arus. Pada saat pasang, akan menyebabkan konsentrasi material padat tersuspensi di pelabuhan tinggi. Begitu juga pada saat surut, konsentrasi material padat tersuspensi juga akan berubah lagi. Secara geografis titik lokasi penelitian berada pada posisi 6040'7,89'S - 6040'22,29"S dan $111^{0} 26^{\prime} 21,34^{\prime \prime} \mathrm{E}-111^{\circ} 26^{\prime} 34,45^{\prime \prime}$. Tujuan dilakukan penelitian ini adalah untuk mengetahui seberapa besar tingkat kekeruhan perairan tersebut serta dampak yang ditimbulkannya. Penelitian ini dilakukan pada bulan November 2018 dengan lokasi daerah pantai Dasun Rembang, Jawa Tengah. Analisis data dilakukan dengan menggunakan bantuan perangkat lunak komputer yaitu Ms Excel, Er Mapper, dan Arc GIS. Materi yang digunakan dalam penelitian ini meliputi data primer yaitu pengamatan lokasi kekeruhan perairan, data pasang surut dan arus, sedangkan data sekundernya yaitu berupa peta rupa bumi Indonesia, data tinggi muka air laut dari satelit. Berdasarkan hasil analisis dari sampel MPT terjadi kekeruhan perairan dengan tingkat sedimenasi yang cukup tinggi. Hasil regresi linier dari data pengamatan pasang surut menunjukan kenaikan sebesar $157 \mathrm{mg} / 1$ - $203 \mathrm{mg} / \mathrm{l}$. Kenaikan muka air laut menyebabkan dampak sedimentasi dimuara sungai pantai Dasun Rembang.
\end{abstract}

Kata kunci : MPT, Pasang Surut, Sedimen Tersuspensi.

\begin{abstract}
Indonesia memiliki laut yang sangat luas dibandingkan dengan daratannya. Luas total wilayah Indonesia adalah 7,81 juta $\mathrm{km}^{2}$ yang terdiri dari 2,01 juta km2 daratan, 3,25 juta $\mathrm{km}^{2}$ lautan, dan 2,55 juta $\mathrm{km}^{2}$ Zona Ekonomi Eksklusif (ZEE). Merupakan suatu Negara dengan luas perairan lebih besar dari pada luas daratan, maka dari itu Indonesia disebut sebagai Negara Maritim. Salah satunya dipulau jawa, tepatnya di daerah jawa tengah. Pantai Dasun terletak di wilayah Kabupaten Rembang, dimana lokasi tersebut sering dijumpai aktivitas kapal nelayan, destinasi wisata, kegiatan industri dan aliran sungai. Proses sedimen tersuspensi dipengaruhi oleh proses-proses yang terjadi di lautan seperti pasang surut dan arus. Pada saat pasang, akan menyebabkan konsentrasi material padat tersuspensi di pelabuhan tinggi. Begitu juga pada saat surut, konsentrasi material padat tersuspensi juga akan berubah lagi. Secara geografis titik lokasi penelitian berada pada posisi $6^{0} 40^{\prime} 7,89^{\prime \prime} S$

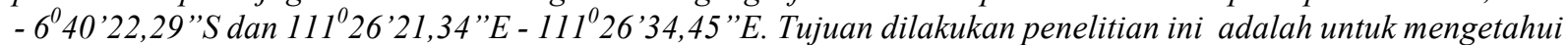
seberapa besar tingkat kekeruhan perairan tersebut serta dampak yang ditimbulkannya. Penelitian ini dilakukan pada bulan November 2018 dengan lokasi daerah pantai Dasun Rembang, Jawa Tengah. Analisis data dilakukan dengan menggunakan bantuan perangkat lunak komputer yaitu Ms Excel, Er Mapper, dan Arc GIS. Materi yang digunakan dalam penelitian ini meliputi data primer yaitu pengamatan lokasi kekeruhan perairan, data pasang surut dan arus, sedangkan data sekundernya yaitu berupa peta rupa bumi Indonesia, data tinggi muka air laut dari satelit. Berdasarkan hasil analisis dari sampel MPT terjadi kekeruhan perairan dengan tingkat sedimenasi yang cukup tinggi. Hasil regresi linier dari data pengamatan pasang surut menunjukan kenaikan sebesar 157 mg/l - $203 \mathrm{mg} / \mathrm{l}$. Kenaikan muka air laut menyebabkan dampak sedimentasi dimuara sungai pantai Dasun Rembang. Keywords: MPT, Tides, Suspended Sediments.
\end{abstract}

\section{PENDAHULUAN}

Indonesia memiliki laut yang sangat luas dibandingkan dengan daratannya. Luas total wilayah Indonesia adalah 7,81 juta $\mathrm{km} 2$ yang terdiri dari 2,01 juta $\mathrm{km} 2$ daratan, 3,25 juta km2 lautan, dan 2,55 
juta km2 Zona Ekonomi Eksklusif (ZEE). Indonesia merupakan suatu Negara dengan luas perairan lebih besar dari pada luas daratan, maka dari itu Indonesia disebut sebagai Negara Maritim dan memiliki perairan atau pantai hampir disetiap kotanya yang berada disepanjang pesisir batas wilayah daratan menuju perairan. Salah satunya dipulau jawa, epatnya di daerah jawa tengah. Pantai Dasun terletak di wilayah Kabupaten Rembang, dimana lokasi tersebut sering dijumpai aktivitas kapal nelayan, destinasi wisata, kegiatan industri. Kegiatan ini tentunya akan berdampak terhadap kondisi perairan salah satunya adalah semakin meningkatnya konsentrasi sedimen tersuspensi. Kondisi hidrooseanografi (arus, gelombang dan pasang surut) merupakan aspek yang berpengaruh secara langsung terhadap sebaran sedimen, dimana sirkulasi arus dan gelombang mampu mentransport massa dan menggerakan sedimen pada suatu tempat ke tempat lainnya pada ruang lingkup yang lebih luas sementara pasang surut berperan dalam sebaran sedimen.

Proses sedimen tersuspensi dipengaruhi oleh proses-proses yang terjadi di lautan seperti pasang surut dan arus. Pada saat pasang, akan menyebabkan konsentrasi material padat tersuspensi di pelabuhan tinggi. Begitu juga pada saat surut, konsentrasi material padat tersuspensi juga akan berubah lagi. Peningkatan konsentrasi sedimen tersuspensi menyebabkan kekeruhan yang dapat mengganggu penetrasi cahaya ke dalam perairan. Keberadaan sedimen tersuspensi dapat mengganggu keseimbangan ekosistem perairan yang pada akhirnya akan berdampak buruk bagi kelangsungan hidup manusia, seperti pendangkalan daerah muara yang mengakibatkan terhambatnya kapal nelayan, punahnya beberapa ekosistem perairan, dan kerusakan lingkungan.

Berdasarkan uraian di atas, dapat diambil langkah awal untuk membantu pengambilan kebijakan dalam masalah di Pantai Dasun dengan melakukan penelitian mengenai proses sedimen material tersuspensi di Pantai Dasun.

\section{MATERI DAN METODE}

Materi yang digunakan pada penelitian ini meliputi data lapangan (data primer) dan data pendukung dari instansi terkait (data sekunder). Data primer meliputi pengukuran pasang surut, sampel air MPT, dan arus. Sedangkan untuk data sekunder meliputi data pasang surut Kabupaten Rembang, peta RBI, dan data pasang surut yang dikeluarkan oleh BIG tahun 2017) yang didapat dari hasil pengukuran sebelumnya yang selanjutnya akan digunakan sebagai data pendukung ataupun sebagai verifikasi.

Pelaksanaan penelitian ini dibagi dalam tiga tahap, yaitu tahap pertama yang meliputi tahap persiapan, tahap kedua pengambilan data, serta tahap ketiga pengolahan dan analisa data meliputi verifikasi dan penarikan kesimpulan.

Tahap pertama merupakan tahap dalam persiapan pengambilan data lapangan pada bulan Oktober 2018 di Tembalang Semarang Provinsi Jawa Tengah.

Tahapan kedua adalah tahap dalam pengambilan data lapangan pada tanggal 22 November - 24 November 2018 di Pantai Dasun Kabupaten Rembang, Provinsi Jawa Tengah. Parameter data yang diambil adalah data pasang surut, sampel air MPT dan data arus laut.

Tahapan ketiga adalah tahap dalam pengolahan data lapangan pada bulan Februari Maret 2019 di Laboratorium Geologi Laut FPIK Universitas Diponegoro. Hasil akan diverifikasi untuk perbandingan dari data pendukung dan data lapangan.

Hasil yang di dapat Pasang surut mempengaruhi sebaran MPT di Pantai Dasun Rembang, hal ini dikarenakan sebaran arus dan terdapat aliran sungai yang merupakan akumulasi material dari darat. Nilai konsentrasi MPT lebih tinggi pada saat pasang dibandingkan saat surut Sebaran MPT lebih tinggi berada di dekat muara sungai sebesar $157 \mathrm{mg} / \mathrm{l}-203 \mathrm{mg} / \mathrm{l}$. 


\section{HASIL DAN PEMBAHASAN}

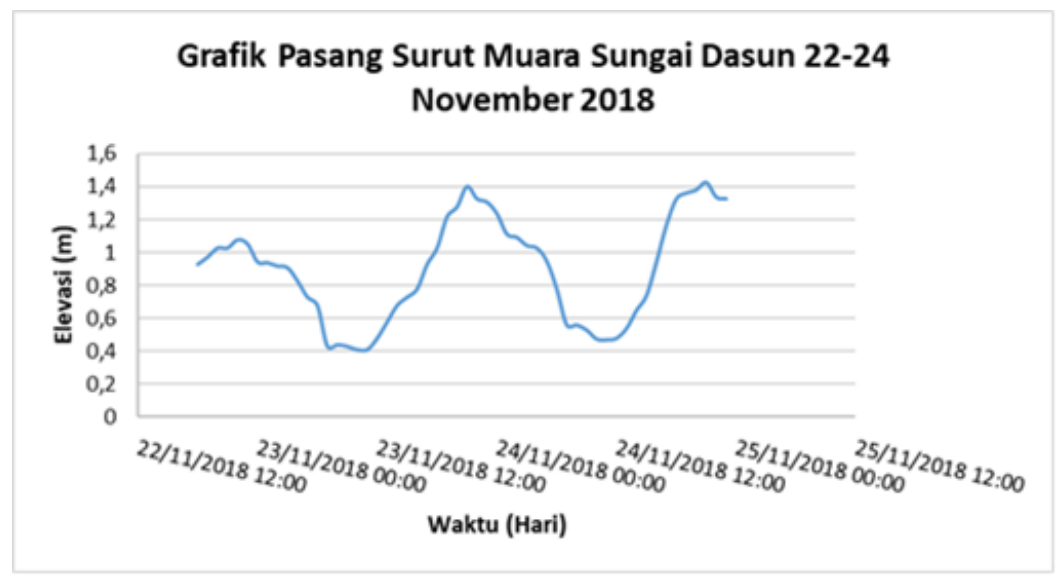

Gambar 1. Grafik pengukuran pasang surut

Dari pengukuran di lapangan diperoleh nilai Tinggi Muka Air Rata-rata (Mean Sea Level) sebesar 95,49 cm, Tinggi Muka Air Tinggi Tertinggi (High Highest Water Level) 181,52 cm dan Tinggi Muka Air Rendah Terendah (Low Lowest Water Level) sebesar 18,18 cm.

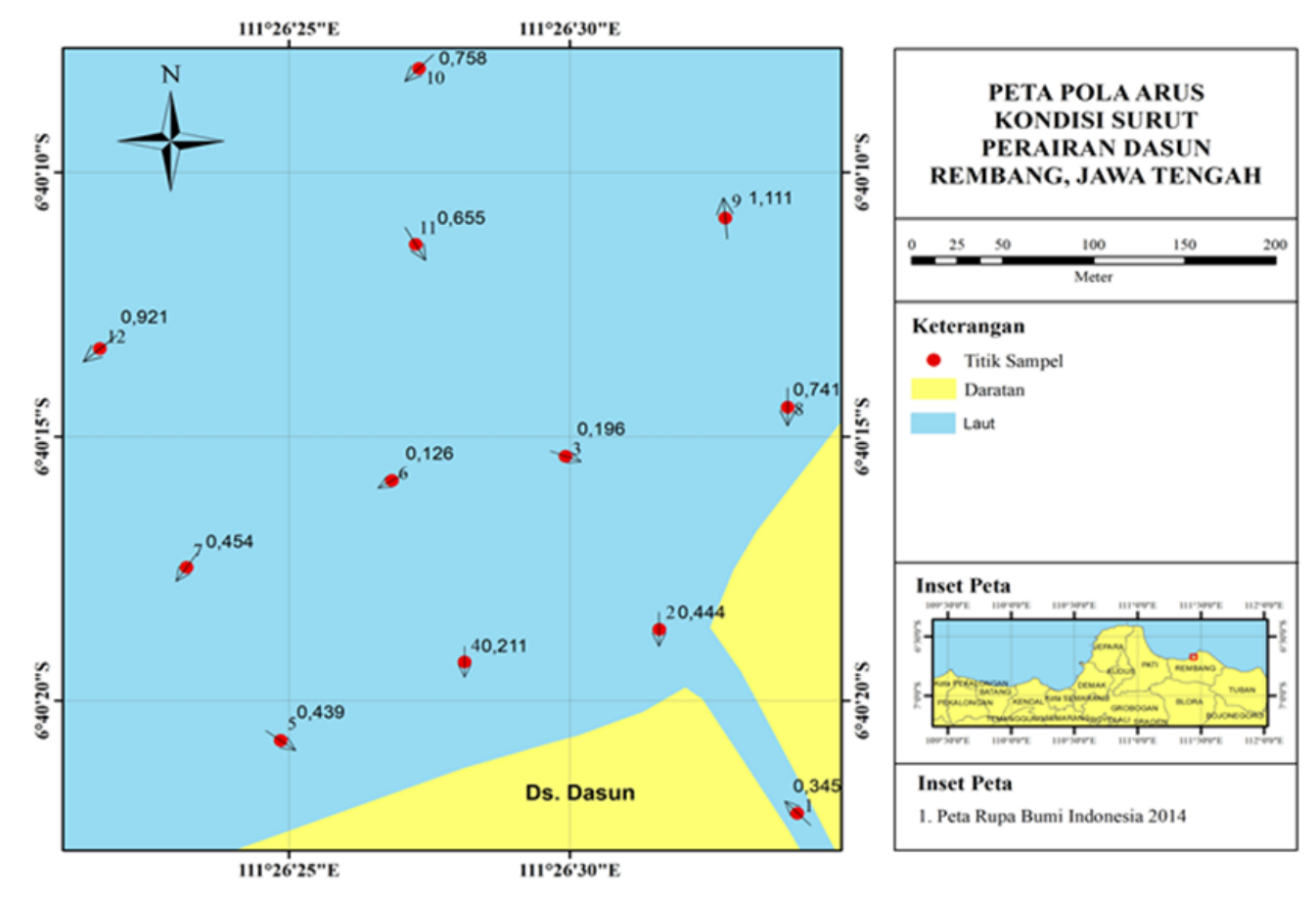

(a) 


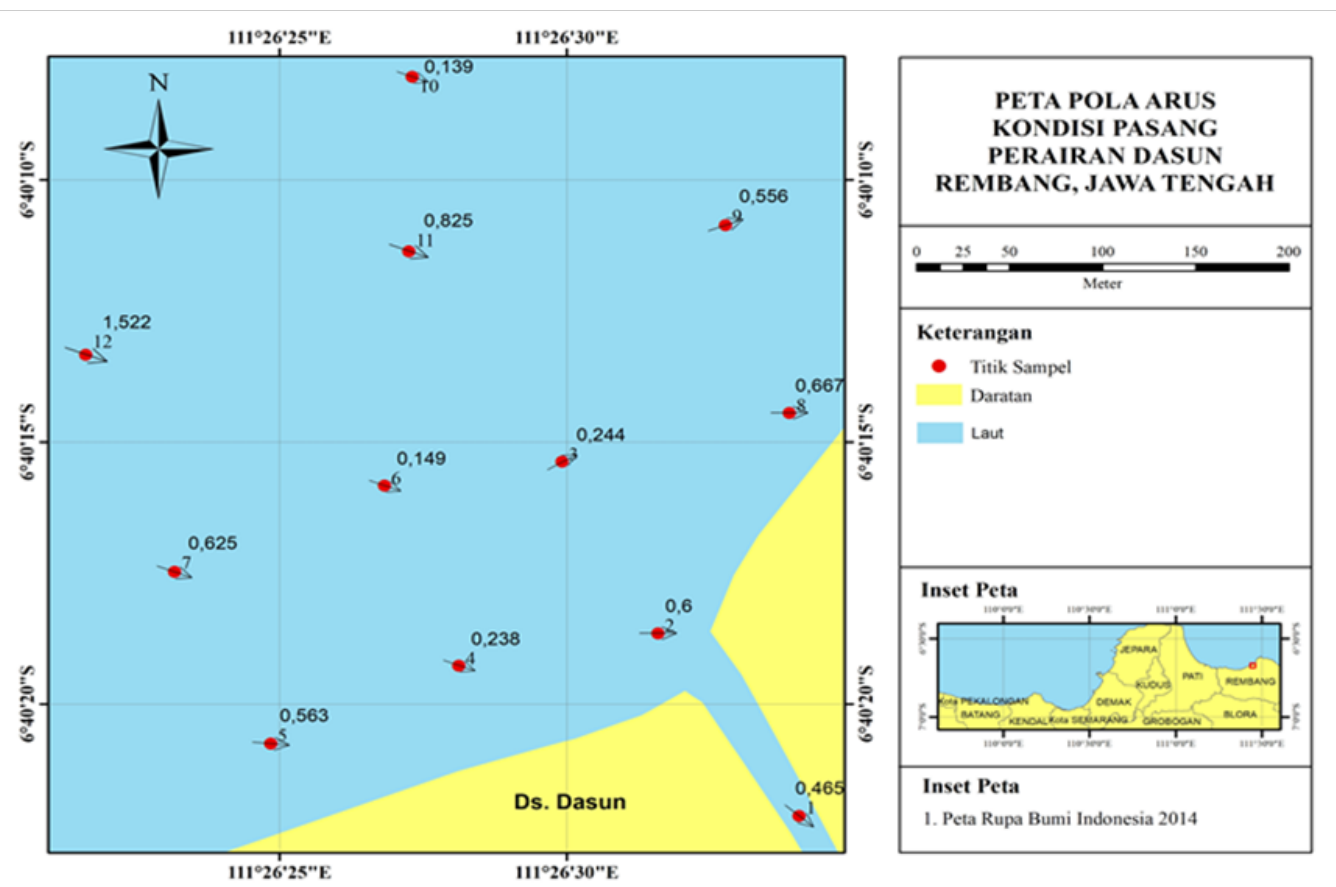

(b)

Gambar 2. Pola arus, (a) peta pola arus pada kondisi purnama saat pasang menuju surut di Pantai Dasun Kabupaten Rembang bulan November 2018, (b) peta pola arus pada kondisi purnama saat pasang menuju surut di Pantai Dasun Kabupaten Rembang bulan November 2018.

Dari hasil dapat dianalisis bahwa Sebaran Material Padatan Tersuspensi (MPT) pada saat pasang dan surut memiliki pola sebaran yang sangat berbeda. Hal ini terjadi karena faktor arus yang mempengaruhi pola sebaran Material Padatan Tersuspensi (MPT) tersebut. Selain itu juga ada faktor aktivitas lingkungan sekitar, pada saat pasang adanya aktivitas pasang sehingga arus dan tinggi gelombang yang sampai di daerah pantai cukup kuat, dimana kecepatan arus berkisar $0.19 \mathrm{~m} / \mathrm{s}-1,44$ $\mathrm{m} / \mathrm{s}$.

Konsentrasi MPT tinggi terdapat pada stasiun 1,2,3 dan 4 sebesar 167-170 mg/l, dikarenakan terdapat aliran sungai yang merupakan akumulasi material dari darat. Disebabkan adanya proses resuspensi yang merupakan proses terlepasnya kembali partikel-partikel dari sedimen yang dapat melarutkan kembali. Besarnya energi sangat tergantung oleh kecepatan angin dan jarak minimum yang dibutuhkan oleh angin untuk membangkitkan gelombang di perairan. Untuk sebaran MPT di permukaan pada kondisi surut umumnya relatif rendah karena air yang mengalir relatif tenang, tidak banyak mendapat gangguan dari arus. Pada saat surut, stasiun dengan tingkat MPT paling tinngi yitu di stasiun 3,4,5 dan 8. Untuk sebaran konsentrasi MPT di lapisan permukaan pada kondisi surut umumnya relatif rendah dibandingkan pada saat pasang. Hal ini disebabkan air lebih tenang dan tidak banyak gangguan arus mengakibatkan sedimen tersuspensi cenderung diendapkan. Namun dalam hal ini lebih besar saat surut, mungkin terjadi faktor eror atau kurang akurat dalam pengukuran sampel di laboratorium.

Hasil analisa dari seluruh kondisi pasang dan surut diketahui bahwa konsentrasi MPT tinggi berada pada kondisi pasang. Dalam hal ini jika angin bertiup di atas permukaan suatu perairan, maka partikel-partikel di bawah akan ikut terbawa, dan gerakan ini akan diteruskan pada partikel air yang lebih bawah. Selain itu, arus juga menyebabkan pengadukan sedimen di perairan sehingga sedimen tersebut larut di dalam air. 


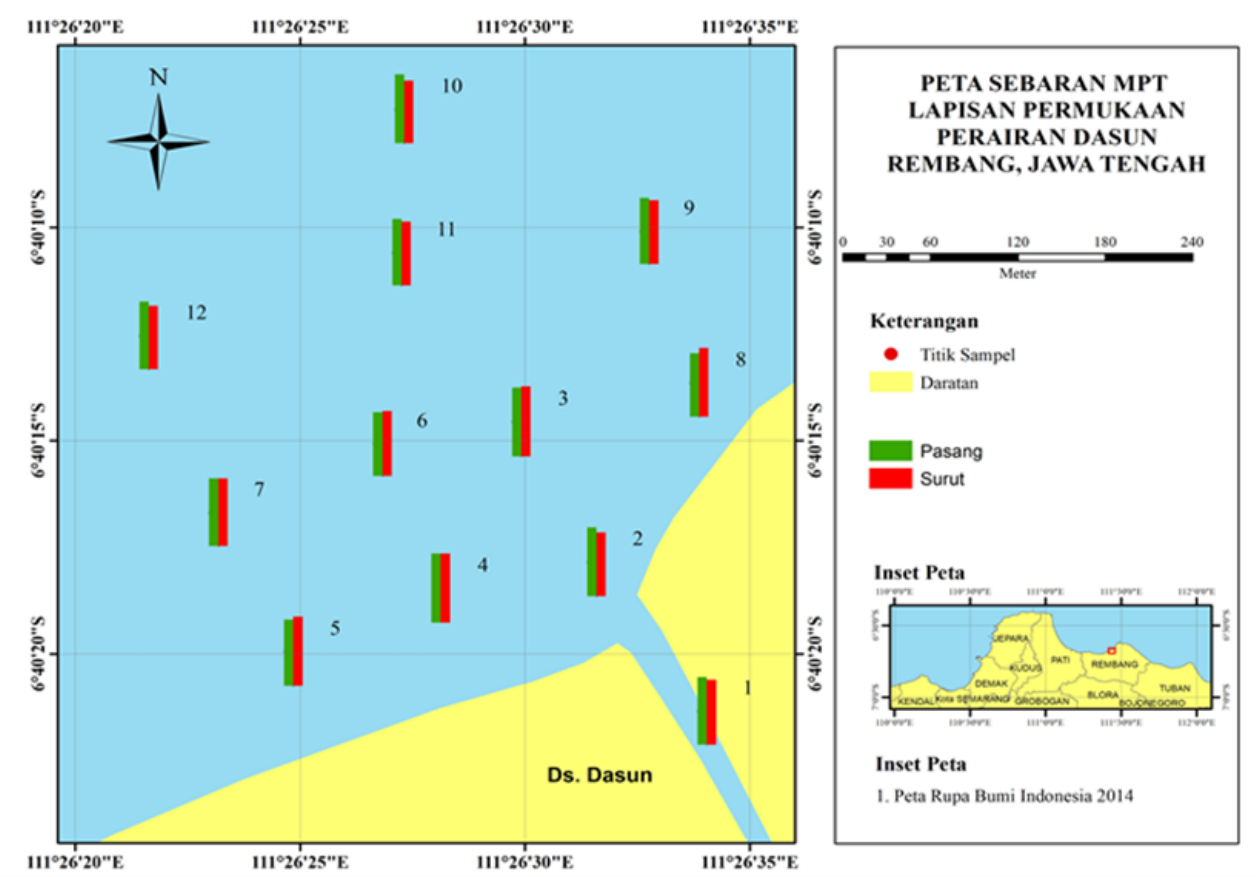

Gambar 3. Sebaran konsentrasi MPT permukaan Pantai Dasun Kabupaten Rembang.

Sebaran Material Padatan Tersuspensi (MPT) selama penelitian pada saat pasang dan surut memiliki tingkat sebaran yang berbeda. Faktor yang mempengaruhi yaitu arus laut dan kondisi lokasi pengambilan sampel yang terdapat sungai dengan aliran dari darat sehingga daerah muara sungai sangat pekat. Berdasarkan gambar 13 pada kondisi pasang, nilai konsentrasi MPT cukup bervariasi sekitar 150 $\mathrm{mg} / \mathrm{l}-170 \mathrm{mg} / \mathrm{l}$. Untuk sebaran konsentrasi MPT di permukaan pada kondisi pasang umumnya relatif tinggi. Hal ini disebabkan pada saat pasang oleh adanya aktivitas pasang sehingga arus dan tinggi gelombang yang sampai di daerah pantai cukup kuat, dimana kecepatan arus berkisar $0.19 \mathrm{~m} / \mathrm{s}-1,44$ $\mathrm{m} / \mathrm{s}$. Konsentrasi MPT tinggi terdapat pada stasiun 1,2,3 dan 4 sebesar 167-170 mg/l, dikarenakan terdapat aliran sungai yang merupakan akumulasi material dari darat. Disebabkan adanya proses resuspensi yang merupakan proses terlepasnya kembali partikel-partikel dari sedimen yang dapat melarutkan kembali. Dalam perairan proses ini diawali dengan energi yang diterima oleh permukaan air melalui angin. Besarnya energi sangat tergantung oleh kecepatan angin dan jarak minimum yang dibutuhkan oleh angin untuk membangkitkan gelombang di perairan. Fetch bergantung pada panjangnya permukaan air di perairan terbuka pada angin yang bertiup, energi ini akan membentuk atau membangkitkan gelombang. Secara umum jika kecepatan angin dan fetch itu besar maka akan menghasilkan tinggi dan periode gelombang yang besar pula, dimana tinggi gelombang maksimal sebesar $0.99 \mathrm{~m}$ dan periode gelombang maksimal sebesar 5.9 detik. Di bawah lapisan permukaan massa air bergerak ke atas. Pada gambar 13 pada kodisi surut, nilai konsentrasi MPT cukup bervariasi sekitar $154 \mathrm{mg} / \mathrm{l}-173 \mathrm{mg} / \mathrm{l}$. Untuk sebaran MPT di permukaan pada kondisi surut umumnya relatif rendah karena air yang mengalir relatif tenang, tidak banyak mendapat gangguan dari arus. Untuk sebaran konsentrasi MPT di lapisan permukaan pada kondisi surut umumnya relatif rendah dibandingkan pada saat pasang. Hal ini disebabkan air lebih tenang dan tidak banyak gangguan arus mengakibatkan sedimen tersuspensi cenderung diendapkan. Namun dalam hal ini lebih besar saat surut, mungkin terjadi faktor eror atau kurang akurat dalam pengukuran sampel di laboratorium. Dari seluruh kondisi pasang dan surut diketahui bahwa konsentrasi MPT tinggi berada pada kondisi pasang. Dalam hal ini jika angin bertiup di atas permukaan suatu perairan, maka partikel-partikel di bawah akan ikut terbawa, dan gerakan ini akan diteruskan pada partikel air yang lebih bawah. Selain itu, arus juga menyebabkan pengadukan sedimen di perairan sehingga sedimen tersebut larut di dalam air. Kondisi pasang secara langsung mempengaruhi jumlah padatan tersuspensi. Padatan tersuspensi di perairan ini umumnya berasal dari erosi yang disebabkan oleh aliran air, buangan rumah tangga dan pembuangan limbah 
industri, dan ekskresi dari organisme perairan (Mc Dowell dan O'conner, 1997). Sedangkan konsentrasi sebaran MPT kecil berada pada kondisi surut.

Pada daerah dekat pantai, sebaran MPT memiliki konsentrasi yang berbeda. Konsentrasi di daerah dekat muara sungai dan pantai, cenderung membentuk endapan dan relatif lebih tinggi dengan kedalaman yang dangkal. Hal ini disebabkan oleh pasang surut yang mengakibatkan terjadinya resuspensi sedimen. Arus yang bergerak sepanjang pantai atau longshore currents yang terbentuk karena gelombang pecah yang membentuk sudut dengan garis pantai (Triatmodjo, 1999).

Dari simulasi mencakup perairan pantai Dasun, pola pergerakan arus di pantai Dasun (gambar 11 - gambar 12) dan dapat dilihat bahwa pola pergerakan arus cenderung memiliki arah bolak-balik secara periodik sesuai dengan kondisi pasang surut yang terjadi. Pada kondisi purnama saat surut menuju pasang (gambar 11), maupun pada kondisi saat pasang menuju surut (gambar 12) menunjukkan arah pergerakan arus yang bergerak dari timur menuju ke barat dan selatan. Hal ini dikarenakan pada daerah timur elevasi lebih besar dari pada elevasi di bagian selatan. Pada perairan dalam keadaan surut menuju pasang dan mengalami pembelokan ketika menabrak breakwater, untuk sebaran MPT dapat dipengaruhi secara langsung oleh sirkulasi arus laut karena sedimen tersuspensi akan bergerak mengikuti arus.

Kondisi perairan dalam keadaan pasang dapat mempengaruhi sebaran MPT karena saat pasang pergerakan arus menuju pantai sehingga kecenderungan MPT dalam konsentrasi tinggi untuk stasiun yang berada di dekat pantai. Sebaliknya arah pergerakan arus yang bergerak dari barat menuju ke timur, pada kondisi purnama saat pasang menuju surut (gambar 12), Hal ini sesuai dengan Ningsih (2002) yang menyatakan bahwa slope muka laut akan mengakibatkan gaya gradient tekanan sehingga akan menimbulkan gerakan arus dari daerah muka laut yang tinggi ke daerah muka laut yang rendah. Jika dilihat dari simulasi, tenaga pembangkit yang utama dalam mekanisme terjadinya arus laut di Pantai Dasun Rembang adalah pasang surut sehingga karakteristik yang dominan dari arus yang terjadi adalah termasuk arus pasang surut. Dari hasil di dapatkan bahwa arus dapat mempengaruhi sebaran MPT, hal ini dipertegas oleh Triatmodjo (1999) yang mengatakan jika dasar laut terdiri dari material yang mudah bergerak, maka arus dan gelombang akan mengerosi sedimen dan membawa searah dengan arus.

Dapat dilihat secara horisontal, baik pasang maupun surut nilai konsentrasi MPT mengalami naik turun dari stasiun 1 sampai stasiun 12 . Nilai tertinggi terdapat pada stasiun 2,3,4 dan 10 sebesar $170 \mathrm{mg} / \mathrm{l}$ pada saat pasang dan stasiun 3 sebesar $173 \mathrm{mg} / 1$ pada saat surut. Sedangkan nilai terendah pada saat pasang terdapat pada stasiun 8 sebesar $150 \mathrm{mg} / 1$ dan pada surut terdapat pada stasiun 10 sebesar $154 \mathrm{mg} / \mathrm{l}$. Hal ini terkait pada kenyataan bahwa MPT terdapat dalam jumlah yang relatif besar di daerah dekat muara sungai. Bila dilihat dari lokasi sampling, maka konsentrasi yang lebih tinggi berada di dekat muara sungai. Hal ini dimungkinkan karena masuknya air sungai dengan partikel MPT ke perairan laut menyebabkan partikel MPT dari sungai tidak dapat keluar ke laut.

\section{KESIMPULAN}

Kesimpulan yang dapat diambil dari penelitian ini yaitu pasang surut mempengaruhi sebaran MPT di Pantai Dasun Rembang, hal ini dikarenakan sebaran arus dan terdapat aliran sungai yang merupakan akumulasi material dari darat. Nilai konsentrasi MPT lebih tinggi pada saat pasang dibandingkan saat surut Sebaran MPT lebih tinggi berada di dekat muara sungai sebesar $157 \mathrm{mg} / \mathrm{l}$ - $203 \mathrm{mg} / \mathrm{l}$.

\section{DAFTAR PUSTAKA}

Alaert, G. dan Santika, S.S. 1987. Metode Penelitian Air. Usaha Nasional. Surabaya, 309 hlm.

Bakti, L.M. 2010. Kajian Potensi Sebaran Rob Kota Semarang dan Usulan Penangananna. Tesis Semarang:Undip.

Chester, R. and Enemy. 1990. Marine Geochemistry. Unwin Hyman Ltd, London.

Djaja R. 1989. Pengamatan pasang surut laut untuk pe-nentuan datum ketinggian. Pasang Surut. Penyunting:Ongkosongo OSR dan Suyarso. Lembaga Ilmu Penge-tahuan Indonesia, Pusat Penelitian dan Pengembangan Oseanologi. Jakarta. p: 149-191. 
Dyer, K.R. 1986. Coastal and Estuarine Sediment Dynamics. John Wiley and Sons, London.

Fadilah, et all. 2014. Menentukan Tipe Pasang Surut dan Muka Air Rencana Perairan Laut Kabupaten Bengkulu Tengah Menggunakan Metode Admiraty. Univrsitas Diponegoro. Semarang.

Effendi, Hefni. 2003. Telaah Kualitas Air Bagi Pengelolaan Sumber Daya dan Lingkungan Perairan. Penerbit Kanisius. Yogyakarta.

Farhudin. 1999. Analisis Arus Laut Perairan Teluk Jakarta. [Tugas Akhir]. Jurusan Geofisika dan Meteorologi FMIPA. Institut Teknologi Bandung. Bandung.

Hadi, S. 1979. Statistik. Cetakan IV. Yayasan Penerbitan Fakultas Psikologi UGM, Yogyakarta.

Hutabarat, S dan S. M. Evans. 1984. Pengantar Oseanografi. Universitas Indonesia Press. Jakarta.

Hutabarat, S dan S. M. Evans. 2008. Pengantar Oseanografi. Cetakan Kedua. Universitas Indonesia Press. Jakarta.

Ilahude G. A. 1999. Pengantar ke Oseanologi. Pusat Penelitian dan Pengembangan oseanologi LIPI. Jakarta. $240 \mathrm{hlm}$.

Kramadibrata, Soedjono. 1985. Perencanan Pelabuhan. Ganeca Exact. Bandung.

Kristanto, P.2002. Ekologi Industri. Penerbit Andi, Yogyakarta.

Latief, H. 2002. Oseanografi pantai. Institut Teknologi Bandung. Bandung.

Mcdowell, M.D. and B.A. O'Connor, (1997) Hydroulic Behaviourod Estuaries, The Memillan Press ltd, London.

Ningsih, Nining Sari. 2002. Oseanografi Fisis. ITB. Bandung.

Nontji, A. 1987. Laut Nusantara. Penerbit Djambatan, Jakarta.

Nontji, A. 1993. Laut Nusantara. P. T. Penerbit Djamabatan, Jakarta, $367 \mathrm{hlm}$.

Ongkosono. 1989. Pusat Penelitian dan Pengembangan Oseanologi. Lembaga Ilmu Pengetahuan Indonesia. Jakarta.

Pariwono, John. 1998. Kondisi Oseanografi Perairan Pesisir Lampung. NRM Secretariat: Jakarta.

Pethick, J. 1984. An Introduction Geomorphology. Chapman and Hall. USA.

Poerbondono dan E. Djunasjah. 2005. Survei Hidrografi. Refika Aditama, Bandung, $166 \mathrm{hlm}$.

Rahman, 2008. Efektifitas Pembelajaran Melalui Penerapan Student Center Learning Pada Mata Kuliah Hidrografi. Lembaga Kajian dan Pengembangan Pendidikan (LKPP) Jurusan Perkapalan Fakultas Teknik Universitas Hasanuddin.

Siebold, E. And W. H. Berger. 1993. The Sea Floor. An Introduction to Marine Geology. Second Edition. Springer - Verlag Berlin. Jerman.

Steward, H. Robert. 2006. Introduction To Physical Oceanography. Department of Oceanography. A \& M University. Texas.

Suryabrata, S. 1983. Metodologi Penelitian, Rajawali Press,Jakarta.

Triatmodjo, B. 1999. Teknik Pantai. Jurusan Teknik Sipil Fakultas Teknik. Universitas Gajah Mada. Yogyakarta. 